\title{
Understanding Consumer Preference for Common Beans from Manifold Viewpoints of Attributes in Dar es Salaam, Tanzania
}

\author{
Ezekiel Swema', Lutengano Mwinuka² \\ ${ }^{1}$ Directorate of Research, Policy and Planning, Tanzania Revenue Authority (TRA), Dar es Salaam, Tanzania \\ ${ }^{2}$ Department of Economics, The University of Dodoma, Dodoma, Tanzania \\ Email: ezzyswema@gmail.com, mwinuka.lutengano@gmail.com
}

How to cite this paper: Swema, E., \& Mwinuka, L. (2021). Understanding Consumer Preference for Common Beans from Manifold Viewpoints of Attributes in Dar es Salaam, Tanzania. Theoretical Economics Letters, 11, 1038-1054.

https://doi.org/10.4236/tel.2021.115066

Received: August 17, 2021

Accepted: October 26, 2021

Published: October 29, 2021

Copyright $\odot 2021$ by author(s) and Scientific Research Publishing Inc. This work is licensed under the Creative Commons Attribution International License (CC BY 4.0).

http://creativecommons.org/licenses/by/4.0/

\begin{abstract}
Common beans appeal to consumers in different ways. One important distinction of this nature is with respect to colour, size, cooking time and gravy quality. When multiple common bean varieties are exposed, consumers normally select several varieties on the same occasion while rejecting some of the offerings. Studies that have explicitly assessed factors underlying such a decision making are confined to demographic and socio-economic factors while ignoring societal and cultural factors. Ignoring these factors distort the measured effects and contribute to the failure of interventions aimed at altering food preferences. This study investigated the factors incorporative for a better understanding of consumers' preferences for common beans. Discrete Choice Experiment was employed in order to elicit individual preference and uncover how individuals selected common beans with varying attribute levels using a random sample of 732 respondents. Using Poisson Regression Model, the results showed that probability of choosing two common bean types was the highest, although for some consumers, the number of choices ranged from zero to eight. Highlighted findings are essential for breeders, farmers and sellers of common beans to become certain on their decisions. The study recommends that breeding and market development efforts should primarily focus on unique preferences of consumers whose choices are predominantly within a narrow range of common beans and hence meeting their varied demand.
\end{abstract}

\section{Keywords}

Attributes, Common Bean, Consumer Preference, Poisson Regression Model, Stated Preference, Tanzania 


\section{Introduction}

Common bean (Phaseolus vulgaris L.) is an important component of the traditional cropping system in developing countries, especially in sub-Saharan African (SSA) (Nassary et al., 2020). More than 101 million smallholder farmers in SSA grow at least one tropical legume (Abate, 2012). The global production of all food legumes has increased at the rate of more than $1 \%$ per annum since 1980 (Nedumaran et al., 2013). Between 1994 and 2019, the growth rate of common bean production in SSA was estimated to be about $4 \%$ per annum although this growth was mainly attributed to an increase in acreage and not crop productivity. However, advances of science and technology have a great role to play in food production. With respect to consumption, the common bean has been reported to exhibit an upward trend in all regions of the world except in Central and East Asia (Nedumaran et al., 2015). Accordingly, SSA is the second largest consumer of common bean, after Latin America and Caribbean region, although its per capita consumption remained constant in the past three decades (FAOSTAT, 2020).

Common bean is regarded as a subsidiary-crop to be relied upon during food shortage or supplement the diet as it is drought resistant and well adapted to the semi-arid regions of the tropics (Akibode and Maredia, 2012). In Tanzania, beans are regarded as important for food and nutrition security as well as income generation (Nassary et al., 2020; Leterme, 2002; Hella et al., 2013). Tanzania is ranked seventh among top producers of common beans worldwide and production is dominated by smallholder farmers who consume part of the product and sell the surplus (Ronner \& Giller, 2013). Farmers with entrepreneurship skills have what it takes to pursue their farming objectives which include producing products that are demanded. However, smallholder farmers in Tanzania have limited entrepreneurial skills and poor access to information about market requirements (Mishili et al., 2011). This information asymmetry limits these farmers from fully benefitting from the increased production because they cannot bargain effectively when they market their produce and locate lucrative outlets for their produce.

For many years, researchers have identified different technologies such as improved seeds for increasing productivity and production of tropical legumes including common bean (Abate \& Orr, 2012; Ronner \& Giller, 2013; Nedumaran et al., 2015). These supply side interventions have paid little attention to market needs, although it is known that attributes embedded in the various varieties of legumes are important in shaping consumer preferences ${ }^{1}$. In essence, breeders have focused almost entirely on producer needs without appreciating the needs of consumers. Abate \& Orr (2012) reveal that absence of direct link between farmers and buyers create demand mismatch which impacts domestic demand in urban markets. Therefore, providing demand-side information is essential for 
farmers and breeders to tailor their production and breeding plans to meet consumers' needs, respectively.

The bean market in Tanzania offers various types of beans that differ by colour, shape, size, cooking time and digestibility (Mishili et al., 2011). These characteristics have been reported to affect consumers' preferences for common beans. Katungi et al. (2011) reported that wealthier households in Kenya preferred low flatulence and large grain size of common beans while poor households were indifferent to size. A study conducted in Tanzania showed that low income earners in Dar es Salaam preferred common bean variety locally known as Soya-kablanketi because of its short cooking time compared to other varieties (Mishili et al., 2011). However, Mundua (2010) found negative relationship between income and willingness to pay for different bean varieties in Uganda, where large grain size and white colour were the preferred bean attributes. A similar study in Kenya reported that women were more conversant with bean attributes than men and made decision about the type of beans to be eaten at home (Gitonga, 2015).

When multiple common bean varieties with varying attribute levels are exposed, consumers normally select multiple varieties on the same occasion while rejecting some of the offerings. Studies that have explicitly assessed factors underlying such a decision making have generally been rare and confined to demographic and socio-economic factors only. Riet et al. (2011) revealed that knowledge from psychology, dietetic and nutritional disciplines is equally important in shaping consumers' food preference. Chadwick et al. (2013) argue that eating habits are partly a reflection of cultural and societal factors that are reinforced through social interactions, community taboos, tastes and preferences. Glanz et al. (1998), for example, reported that most individuals prefer to eat foods that are familiar to them and resist acquiring new preferences. According to Alessandro and Luisa (2014), factors influencing food choice decisions are interactive, encompassing societal, emotional cultural and other individual-specific factors. If these factors are studied together, the measured effect of consumer decision making about food could be revealed. Regardless of their importance in shaping consumer preferences, cultural and societal factors have not been given enough attention in the previous studies. Ignoring these factors can distort the measured effect of the studied factors (i.e., demographic and socio-economic factors) and contribute to failure of interventions aimed at altering food preferences. This study incorporates cultural and societal aspects that were not taken into consideration in previous studies along with demographic and socio-economic aspects in order to get a better understanding of consumer preference for common beans in Dar es Salaam. Filling this gap would support entrepreneurs and other stakeholders seeking to do business or improve their business in the common bean sub sector. This endeavor would also help to identify opportunities to facilitate the development of the value chain and enhance income and reduce poverty. 


\section{Theoretical Framework}

The study employed the demand theory which asserts that goods as such, are not the immediate objects of preference or utility or welfare, but have associated characteristics which are directly relevant to consumers (Lancaster, 1966). If the consumer is required to make independent choices among various common bean types, the choice to be made reflects unobserved utility. This utility is derived from the attributes' embedded in the chosen common bean type which varies across individuals depending on their demographic, socio-economic, cultural and societal characteristics.

The utility function is specified as,

$$
U_{i j}=f\left(A t t_{j}, S_{i}\right)+\varepsilon_{i}
$$

where, $U_{i j}$ is the utility of the $I^{\text {th }}$ individual derived from $f^{\text {th }}$ type of common beans, $A t t_{j}$ is the $f^{\text {th }}$ specific attributes embedded in, $S_{i}$ represents individual specific characteristics and $\varepsilon_{i}$ is the stochastic error for the $i^{\text {th }}$ individual. However, the random utility model (Equation (1)) is appropriate when individuals are able to rank the choices based on perceived satisfaction derived from each type of common bean (Louviere et al., 2000). If an individual is not required to rank the possible choices, the random utility model is replaced by the latent model specified in Equation (2). The attributes component in Equation (1) is left out in Equation (2) because individuals are exposed to specific type of common bean at a time.

$$
y_{i}^{*}=f\left(S_{i}\right)+v_{i}
$$

where, $y_{i}^{*}$ reflects the perceived net benefits from a given common bean type, $S_{i}$ reflects individual specific characteristics and $v_{i}$ is the stochastic error for the $I^{\text {th }}$ individual.

Then, $I^{\text {th }}$ individual in Equation (2) will choose a specific common bean type based on the perceived net expected benefits derived from such type. The choice decisions rule is expressed in Equation (3).

$$
\left.\begin{array}{l}
y_{i}^{*}>0 \text { specific common bean type is selected by } i^{\text {th }} \text { individual } \\
y_{i}^{*} \leq 0 \text { specific common bean type is rejected by } i^{\text {th }} \text { individual }
\end{array}\right\}
$$

If the perceived net expected benefits are greater than zero, the specific common bean type is selected and if the perceived net expected benefits are less or equal to zero the specific common bean type is rejected.

\section{Materials and Methods}

\subsection{Data Collection}

Data were collected from Dar es Salaam city to represent beans consumers in Tanzania. The selection of this city was purposeful because it is the major market for common beans in the country and business centre (market share of about 26\%). Moreover, Dar es Salaam has diverse population to account for variation 
in social, ethnic and economic background of bean consumers. A three-stage sampling design was employed in this survey. The first stage involved stratification of the enumeration areas (EAs) within the city into high, middle and low income residences to ensure fair representation of such consumers' categories. The second stage entailed a proportionate sampling of 100 EAs from the three strata. The third stage involved a random selection of eight households from each of the 100 EAs resulting into a sample of 732 households. This sample is less than the desired one of 800 due to incompleteness and poor quality of information that were solicited from 68 targeted household heads. A household survey was conducted in all three districts of Dar es Salaam city, Tanzania namely Kinodoni, Temeke and Ilala. A household survey was accompanied with a Discrete Choice Experiment to gather information on a household and respondent specific factor that could influence consumers' preferences for common beans' types. The choice task was first comprehensively introduced to the respondents (household heads) to make sure the task of choosing common beans with specific attributes were properly understood. A pilot test before the actual choice experiment confirmed the respondent understanding of the choice task.

\subsection{Discrete Choice Experiment}

The discrete choice experiment (DCE) was employed in order to elicit individual preference and uncover how household heads selected common bean types by asking them to state their choice over different hypothetical attributes combinations. Four different common beans' attributes were identified to include colour, grain size, cooking time and gravy quality. The colour attribute involved four colours namely pure grey locally known as soya-supa, grey locally known as soya-kawaida, yellow locally known as soya-njano and mottled-red. The grain size attribute involved three classes of size namely small, medium and large. The cooking time attribute involved common beans that cook fast and those that cook slowly. Finally, the gravy quality attribute was specified in two levels namely poor and good gravy quality. Among the four attributes, common bean color was considered as the very first factor attribute underlying consumers' choices followed by other attributes of beans such grain size, cooking time and gravy quality. The common bean colors involved in this experiment are presented in Plate 1.

The experiment generally intended to capture trade-offs among the attributes in the common bean types. Therefore, specific common bean with specific color was physically presented to household heads and traded off with other attributes such as grain size, cooking time and gravy levels to produce the preference. Following the given four attributes with their levels, its combination $(4 \times 3 \times 2 \times 2)$ gives the rise of 48 common bean types. From the 48 common bean types, 6 unique choice sets were created each containing 8 different types of common bean. The total sample of respondents was divided into 6 sub-samples and each was subjected to only one of the 6 choice sets. 


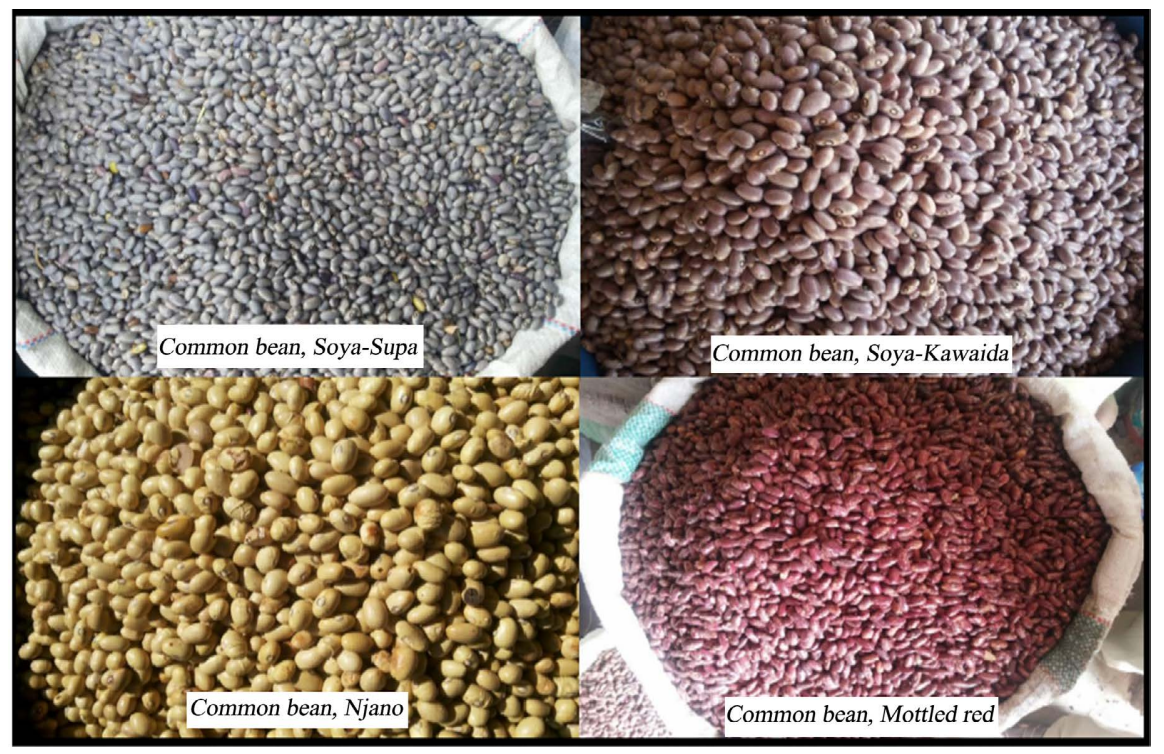

Plate 1. Common beans colours involved in choice experiment.

\subsection{Data Analysis}

The data was analyzed by a combination of descriptive statistics and Poisson regression model. Descriptive statistics were used to determine what common bean types were chosen by the majority of household heads and which ones were chosen by least number of respondents in each of the 6 choice sets. Let $n_{s}$ be the sample size related to choose set $S$ where $(s=1,2, \cdots, 6) ; n_{j s}$ be the number of individuals selecting a specific type of common bean from set $S$. Then, $f_{j s}=n_{j s} / n_{s} * 100$ represents the percentage of respondents choosing common bean $j$ from set $s$.

Therefore, for each choice set (s), the elements J's for $J=1,2, \cdots, 8)$ and that the $J$ 's are different from one choice set to another) were listed in descending order based on $J_{j s}$. The common bean types that listed first from each choice set were chosen to construct a pattern of most chosen common bean types. Similarly, a pattern of least chosen common beans was constructed by choosing those types that listed last from each choice set. A Poisson Regression Model (PRM) was used to analyse factors influencing number of common bean types made by the consumer in six different choice sets. The analysis shows the range of choice among consumers given their stated preferences/choices of common bean types. Equation (4) presents the Poisson probability function, with $Y$ being the corresponding random variable, the probability of choosing common bean type within a given choice set. For each choice set, there are 8 different common bean types. The range of selecting these types in each choice set is conditioned from not selecting any type to selection of all 8 types of common beans, hence presenting a non-negative integer condition of Poisson model.

$$
\operatorname{Pr}\left(Y=y_{i} \mid X_{i}\right)=\frac{\mathrm{e}^{-\lambda_{i}} \lambda_{i}^{y_{i}}}{y_{i} !}
$$




$$
\left\{\begin{array}{l}
y_{i}=0 \rightarrow \text { No common bean type chosen by } i^{\text {th }} \text { individual } \\
y_{i}=8 \rightarrow \text { All types of common bean are chosen by } i^{\text {th }} \text { individual }
\end{array}\right.
$$

$\lambda_{i}$ represents the expected number of common bean types chosen by individual $i$. Suppose we let expected number of choices $\lambda_{i}$ (and therefore the variance) depend on a vector of explanatory variables $X_{i}$. A simple liner model is given as:

$$
\lambda_{i}=\mu(x)=\mathrm{e}^{x_{i}^{\prime} \beta}
$$

Because the Poisson mean on the left-hand side represents an expected count and must be non-negative, a simple linear model shown in Equation (5) was modelled by applying logarithm in both side to get a linear model as:

$$
\log \left(\lambda_{i}\right)=X_{i}^{\prime} \beta
$$

Since for poison distribution the mean equals to the variance, this gives rise to Equation (7)

$$
E\left[y_{i} / x_{i}\right]=\operatorname{Var}\left[y_{i} / x_{i}\right]=\lambda_{i}=\mathrm{e}^{x_{i}^{\prime} \beta}
$$

The $y_{i}^{\prime}$ are independently distributed as Poisson random variables with mean $\lambda_{i}$ for each individual. So, the Poisson regression model may be written as:

$$
\log _{e}\left(\lambda_{i}\right)=\underset{\sim}{X} \underset{\sim}{\prime}
$$

where $\lambda_{i}$ is the response variable indicating the expected number of common bean type chosen by $I^{\text {th }}$ consumer, $X_{i}$ is a vector of independent variables influencing the number of common bean varieties chosen by the $I^{\text {th }}$ consumer and $\beta$ represents a vector of parameters estimated.

\subsection{Variable Estimations and Diagnostic Tests}

Marginal effects provide a way of measuring the effect of each explanatory variable on the dependent variable. The marginal effect of one explanatory variable is the expected instantaneous rate of change in the dependent variable as a function of the change in that covariate while keeping other covariates constant for PRM from Equation (6).

$$
\frac{\partial E\left(Y_{i} / X_{i}\right)}{\partial X_{i j}}=\beta_{j} \mathrm{e}^{x_{i}^{\prime} \beta}=\beta_{j} E\left(y_{i} / x_{i}\right)
$$

Therefore, the marginal effect of the change in regressor $x_{i, j}$ depends not only on $\beta_{j}$, but also on all other estimated coefficients and on all other values. Because the derivative in Equation (9) is with respect to a small change, it is not appropriate to apply for the effect of a change in a dummy variable, or change of state. The appropriate marginal effect for the dummy variable, say, $d$, would be;

$$
\text { Marginal Effect }=\operatorname{Prob}\left[Y=1 \mid x_{(d)}, d=1\right]-\operatorname{Prob}\left[Y=1 \mid x_{(d)}, d=0\right]
$$

where $x_{(d)}$ denotes the means of all the other variables in the model. 
The results from the model were assured for validity of Poisson distribution assumptions and goodness of fit. Pseudo $\mathrm{R}$ squared was used to check for the model fitness. A conditional moment test was used to test for over dispersion in the model (the major assumptions in Poisson distribution i.e. mean should be equal to variance). An over dispersion test starts from the hypothesis in Equation (10).

$$
\left.\begin{array}{l}
H_{0}: \operatorname{Var}\left[y_{i}\right]=E\left[y_{i}\right] \\
H_{1}: \operatorname{Var}\left[y_{i}\right]=E\left[y_{i}\right]+\alpha \rho\left(E\left[y_{i}\right]\right)
\end{array}\right\}
$$

Simple comparisons based procedure for testing the hypothesis (Equation (10)) is carried out by comparing the values for mean and variance of the expected number of choices. If the expected variance happens to be greater than the expected mean, over dispersion in the model is confirmed. If it happens that the expected variance is equal to expected mean or the expected mean are greater than expected variance with small variations (less than 0.5 ) the model is confirmed not have over dispersion.

\section{Results and Discussion}

\subsection{Most and Least Chosen Common Bean Types}

On the basis of the available data and design of the choice experiment a list of most and least chosen common bean types are presented in Table 1 and Table 2 respectively. For example, according to Table 1, common bean type with grey colour, large grain size, fast cooking and whose gravy quality is good was chosen by majority of consumers in the first choice set. The rest of most and least chosen common bean types with specific attributes and specific choice set are as presented in Table 1 and Table 2.

The common bean attributes such as yellow colour, large size and good gravy quality appeared to dominate the list of most chosen common bean types by consumers in Dar es Salaam. Evidence from several studies concurs with this observation (Mishili et al., 2011; Katungi et al., 2011; Gitonga, 2015). Common

Table 1. Most chosen common beans' types.

\begin{tabular}{crccc}
\hline Choice Set* & Common bean type & N & $\begin{array}{c}\text { Absolute } \\
\text { frequency }\end{array}$ & Percentage \\
\hline 1 & Grey, Large, Fast, Good & 119 & 84 & 70.6 \\
2 & Yellow, Medium, Slow, good & 123 & 61 & 49.6 \\
3 & Yellow, Large, Fast, Poor & 124 & 70 & 43.9 \\
4 & Mottled-red, Large, Slow, Poor & 130 & 57 & 61.6 \\
6 & Yellow, Large, Fast, Good & 112 & 69 & 62.9 \\
\hline
\end{tabular}

* Sets of common bean types exposed to consumers. Each set comprised of 8 common bean types. The common bean types that shown are those selected by majority of consumers in each choice set. 
Table 2. Least chosen common beans' types.

\begin{tabular}{ccccc}
\hline Choice Set $^{*}$ & Common bean types & N & $\begin{array}{c}\text { Absolute } \\
\text { frequency }\end{array}$ & Percentage \\
\hline 1 & Pure grey, Small, Fast, Poor & 119 & 0 & 0 \\
2 & Mottled red, Medium, Slow, Poor & 123 & 13 & 10.6 \\
3 & Pure grey, Medium, Slow, Poor & 124 & 8 & 6.5 \\
4 & Grey, Small, Slow, Good & 130 & 14 & 10.8 \\
5 & Grey, Large, Slow, Poor & 112 & 24 & 21.4 \\
6 & Pure grey, Small, Slow, Poor & 124 & 2 & 1.6 \\
\hline
\end{tabular}

${ }^{*}$ Sets of common bean types exposed to consumers. Each set comprised of 8 common bean types. The common bean types that shown are those selected by least number of consumers in each choice set.

beans with yellow colour are preferred because they are associated with lowest cooking time (about 75 minutes) compared to beans with other colours (Mishili et al., 2011).

Similarly, the majority of low income consumers prefer fast cooking beans to save on cooking fuel (Katungi et al., 2011). Therefore, the results potentially explain why the majority of consumers will choose common beans with yellow colour which are associated with fast cooking attribute. In comparison with other colours involved in the choice experiment, yellow colour was dominant in the list of most chosen common bean types as indicated in Figure 1.

Literature suggests that large sized grains expand more when cooked than the small sized grains of common beans (Gitonga, 2015). Saba et al. (2015) studied on swelling capacity of common bean, they found that common bean with large size expand/swell more when cooked than those with small size. Therefore, it makes sense that fewer amount of common bean with large grain size would be required to make a meal compared to when the common bean is of small grain size. This is however the reason why common bean with large grain size are chosen most by consumers compared to common bean with small grain size. In terms of gravy quality common bean with good gravy quality were observed to dominate the list of most preferred common beans' types. Several studies have identified good gravy to influence food preference (Wahl et al., 2017; Cohen and Babey, 2012; Chadwick et al., 2013). Table 2 shows that common bean attributes such as pure grey colour, small size and poor gravy quality observed to be chosen by least number of consumers. According to Ronner and Giller (2013) common beans with this character (pure grey colour) are associated with higher prices compared to beans with other colours. These type of beans are mainly sold in supermarkets were majority of consumer with low and medium income not obvious doing their purchases. The domination of pure grey colour compared to other colour of common beans involved in the DCE is as shown in Figure 1. 


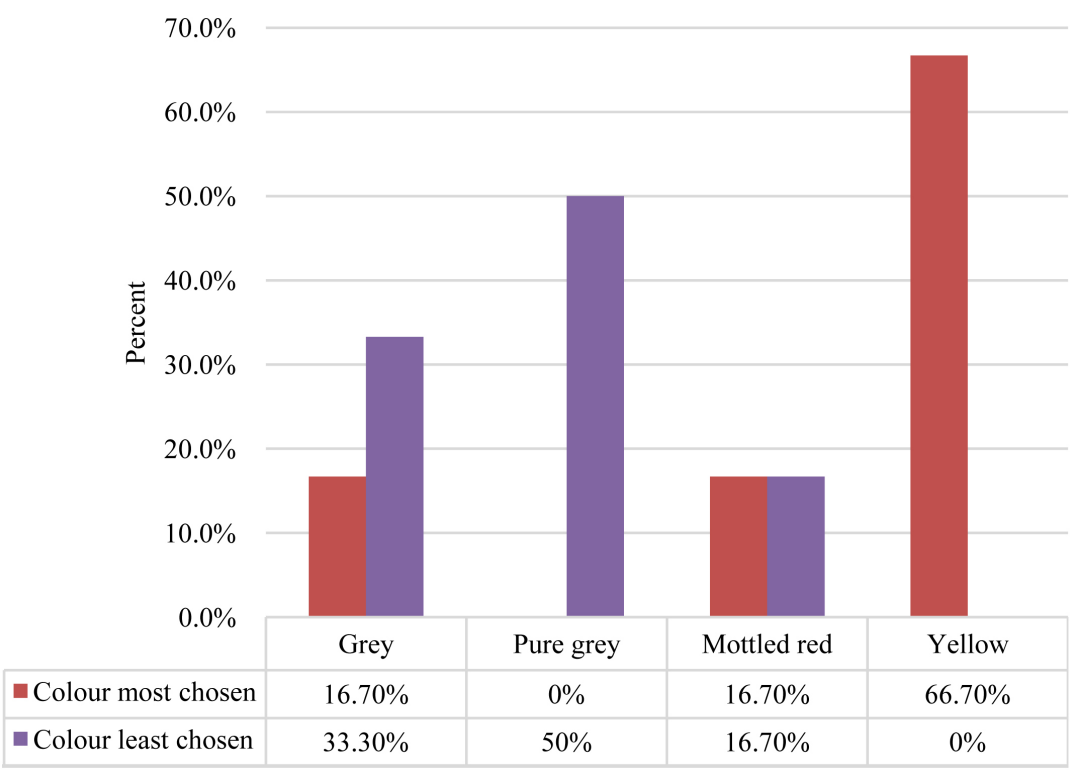

Figure 1. Most and least chosen common bean colour.

\subsection{Range of Choice(s) of Common Bean Types}

In order to explore the current and future demand of different common bean types, a clear understanding on how consumers are flexible in choosing those beans is crucial. This message is important for both sellers and breeders of common bean in a bean sub sector. In this study, 8 common bean types were presented to a consumer and asked to state if the bean would be chosen or rejected. At the end of the experiment the number of selected bean type ranged from 0 (no bean selected) to 8 (all beans selected). Consumers were considered being flexible in choices if they choose at least two types and not flexible if they stick to the choice of only one type of common bean. If consumer choose nothing from the given common bean types, he or she was considered not having a habit of eating beans.

Results in Figure 2 present how consumers are diverse in choices of common bean types. They ranged from choosing nothing to all eight type of common bean that were provided during the experiment. However, the results showed that after the choice of two common bean types, probability of choice decreases as the number of choices increase. In a set of eight common bean types, majority of consumers were flexible in choosing two types of common bean, however chances of choosing all eight types were observed to be minimal.

The number of choices of common bean types were ranked corresponding to probability of choice as presented in Table 3. A ranking results revealed that majority of consumers confined in choosing one type of common bean to four types of common bean. The probability of consumers to stick on choice of only one type observed to be $20 \%$, meaning they are not flexible in their choice. Also, the sum of probabilities of choosing more than one type of common bean observed to be $79 \%$. This is to mean that majority of consumers who were involved 


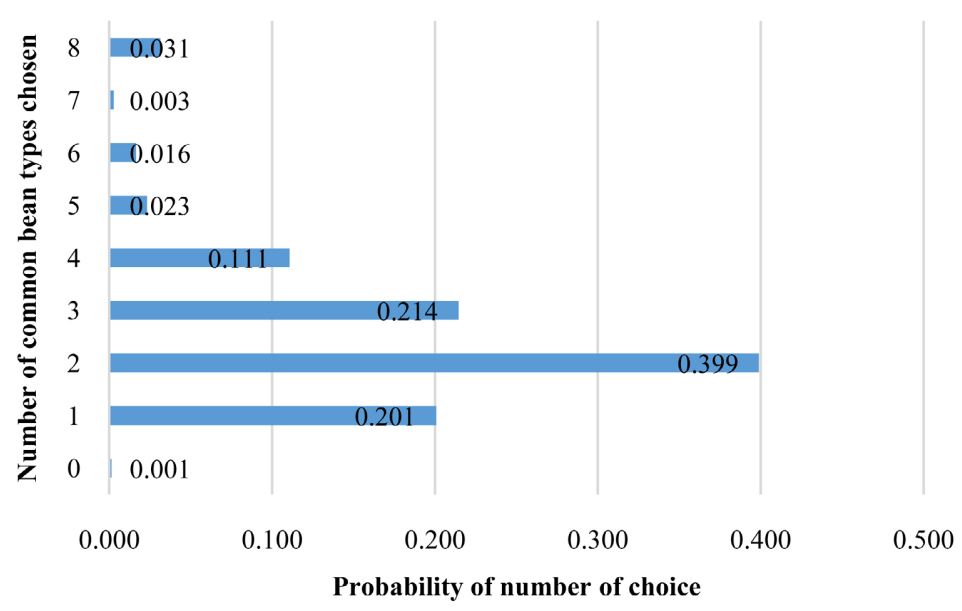

Figure 2. Average probability of choosing zero, one or more common bean types.

Table 3. Ranking number of choice of common bean by probability.

\begin{tabular}{cccc}
\hline $\begin{array}{c}\text { Number of common } \\
\text { bean types chosen }\end{array}$ & Rank & $\begin{array}{c}\text { Probability of number of } \\
\text { common bean type chosen }\end{array}$ & CDF \\
\hline 0 & 9 & 0.00 & 0.00 \\
1 & 3 & 0.20 & 0.20 \\
2 & 1 & 0.40 & 0.60 \\
3 & 2 & 0.21 & 0.81 \\
4 & 4 & 0.11 & 0.92 \\
5 & 6 & 0.02 & 0.94 \\
6 & 7 & 0.02 & 0.96 \\
7 & 8 & 0.00 & 0.96 \\
Total & 5 & 0.03 & 1.00 \\
\hline
\end{tabular}

in this study are flexible in their choices with high proximity of trading off between two to four different types of common bean. Factors affecting this type of behaviour are discussed in the next section.

\subsection{Factors Affecting Mean Number of Choice of Common Bean Types}

Table 4 presents how data used in this study are distributed. Although the study includes consumers from the Dar es Salaam region, participants represented a wide range of characteristics such as demographic, socio-economic, cultural and societal aspects. Household size ranged between 1 member to 11 members, age ranged between 16 and 92 years, years of schooling ranged from 0 to 18 years and total household income ranged from Tanzanian Shillings (TAS) 3000 per month to TAS 250,000 per month. With regards to the habit of consuming beans, majority of respondent observed to possess habit of eating beans. 
Table 4. Summary statistics of variable included in a Poisson regression model.

\begin{tabular}{|c|c|c|c|c|c|}
\hline Continuous variables & $\begin{array}{l}\text { Number of } \\
\text { respondents }\end{array}$ & Median & $\begin{array}{c}\text { Std. } \\
\text { Deviation }\end{array}$ & Min & $\operatorname{Max}$ \\
\hline Household size & 732 & 4 & 2.25 & 1 & 11 \\
\hline Age of the household head (Years) & 732 & 33 & 13.35 & 16 & 92 \\
\hline Level of education (Years) & 732 & 7 & 3.95 & 0 & 18 \\
\hline Income of a household head (TAS) & 732 & 4375 & $11,489.14$ & 3000 & 250,000 \\
\hline Categorical variables & \multicolumn{2}{|c|}{$\begin{array}{l}\text { Percentage } \\
(\mathrm{n}=732)\end{array}$} & & & \\
\hline \multicolumn{6}{|l|}{ Sex of household head } \\
\hline Male & 86.7 & & & & \\
\hline Female & 13.3 & & & & \\
\hline \multicolumn{6}{|l|}{ Marital Status } \\
\hline Single & 23 & & & & \\
\hline Married & 77 & & & & \\
\hline \multicolumn{6}{|l|}{ Occupation of head of household } \\
\hline Employed & 35.8 & & & & \\
\hline Unemployed & 64.2 & & & & \\
\hline \multicolumn{6}{|l|}{$\begin{array}{l}\text { Household head domestic } \\
\text { place of origin }\end{array}$} \\
\hline Bean producing regions & 33.3 & & & & \\
\hline Non bean producing regions & 66.7 & & & & \\
\hline \multicolumn{6}{|l|}{ Custom of head of household } \\
\hline Habit of eating beans & 95.5 & & & & \\
\hline No bean eating habit & 4.5 & & & & \\
\hline \multicolumn{6}{|l|}{ Household food purchase decision } \\
\hline Household head & 62.2 & & & & \\
\hline All family members & 37.8 & & & & \\
\hline
\end{tabular}

The Poisson regression model was used to determine factors affecting the mean number of common beans' types chosen by consumers. Results were tested for model goodness of fit and Poisson distribution assumption. Pseudo $\mathrm{R}$-squared was 0.16 indicating modest level of fitness. According to Louviere et al. (2000) the pseudo R-squared should be greater than 0.1 to have a stable or meaningful model whereas a value between 0.2 and 0.4 is considered as an extremely good fit. Poisson regression model is rejected when there is over-dispersion in the dependent variable (i.e. variance $>$ mean). Table 5 indicates non-presence of over-dispersion since mean of the dependent variable is slightly greater than variance. According to Cameron \& Trivedi (1986), if the mean is greater than variance with a small variation $(<0.5)$, the means are said to be roughly equal to 
Table 5. Detection of over-dispersion.

\begin{tabular}{cc}
\hline \multicolumn{2}{c}{ Number of common bean types chosen by individuals } \\
\hline Number observations & 732 \\
Mean & 2.569672 \\
Std. Deviation & 1.487498 \\
Variance & 2.212649 \\
\hline
\end{tabular}

the variance. For this reason, the distribution of the dependent variable was observed to comply with the Poisson distribution assumption.

Table 6 presents results of factors affecting the mean number of common bean type chosen by consumers. On number of choice made, common bean type chosen by female-headed households is $30.3 \%$ higher than for male counterparts, ceteris paribus. As expected, this is an indication that female headed households are more flexible in their choice of common bean types as compared to male headed households. However, factors such as household size, marital status, and age were observed not to significantly influence number of common bean type chosen by consumers.

Socio-economic variables including income of a household head, occupation and level of education showed a significant influence on number of choice of common beans' types. Although household's head income indicated highest level of significant influence on the number of common bean type chosen, its influence on choice was observed to be relatively small. The results also showed a positive relationship between income and mean number of choice of types of common beans. Previous studies indicated that individuals with high level of income are deemed able to try out specific food with multiple attributes assuming different attributes implicitly refer to different quality levels (Abdullahi Farah et al., 2011; Ogundele, 2014).

Being employed increased the number of choices of common bean types by about $50.4 \%$, ceteris paribus. This finding is similar to that of Lima et al. (2021) that revealed high possibility of employed individuals to interact with people and acquiring new knowledge on various types of food and food habit than unemployed people. Also, according to Devine et al. (2009) and Blake et al. (2011), working conditions are associated with food choices coping strategies and influences different food selection at home. An additional year of formal learning is likely to increases the number of choice of common beans' type by about $28.5 \%$ when other factors are held constant. This finding validates the previous studies that found higher levels of awareness on healthy eating among educated than uneducated people (Parraga, 1990; Leterme, 2002). More education is also associated with curiosity and ability to search and try new food products with different but desired attributes (Vartanian et al., 2008; Riet et al., 2011). 
Table 6. Factors affecting number of common bean types chosen: Poisson regression results (marginal effects).

\begin{tabular}{|c|c|c|c|c|}
\hline Variable & $(d y / d x)$ & Std. Err. & $\mathrm{z}$ & $P$-Value \\
\hline \multicolumn{5}{|c|}{ Demographic factors } \\
\hline Sex of the household head & 0.3894 & 0.0668 & 5.83 & $0.000^{* * *}$ \\
\hline Household size & -0.0190 & 0.0165 & -1.15 & 0.248 \\
\hline Marital status & -0.1174 & 0.0855 & -1.37 & 0.170 \\
\hline Age of a household head & 0.0008 & 0.0721 & 0.01 & 0.991 \\
\hline \multicolumn{5}{|c|}{ Socio-economic factors } \\
\hline Income of a household head & $5.75 e-06$ & 0.0000 & 3.47 & $0.001^{* *}$ \\
\hline Occupation of head of household & 0.50488 & 0.0726 & -6.96 & $0.000^{* * *}$ \\
\hline Education of a household head & 0.2855 & 0.0576 & -4.96 & $0.000^{* * *}$ \\
\hline \multicolumn{5}{|c|}{ Cultural and societal factors } \\
\hline Household head domestic place of origin & 0.2009 & 0.0662 & 3.03 & $0.002^{* *}$ \\
\hline Bean eating habit & -0.5919 & 0.4233 & -1.40 & 0.162 \\
\hline Household food purchase decision & 0.2040 & 0.0690 & 2.95 & $0.003^{* *}$ \\
\hline \multicolumn{5}{|c|}{ Number of Observations $=732$} \\
\hline \multicolumn{5}{|c|}{$\operatorname{LR} \operatorname{chi}^{2}(16)=1226.34$} \\
\hline \multicolumn{5}{|c|}{ Prob $>\mathrm{chi}^{2}=0.000$} \\
\hline \multicolumn{5}{|c|}{ Log likelihood $=-3218.1122$} \\
\hline \multicolumn{5}{|c|}{ Pseudo $\mathrm{R}^{2}=0.1600$} \\
\hline
\end{tabular}

Significance levels are denoted by ${ }^{* * *}$ for $1 \%$ and ${ }^{* *}$ for $5 \%$.

With respect to societal/cultural variables, household head domestic place of origin and food purchase decisions observed to significantly influence the number of choices made at $5 \%$ level. For the household domestic place of origin, the mean number of common bean type chosen by consumers originated from major bean producing areas is $20 \%$ higher than those originated from least or non-bean producing areas. This is to mean that, consumers originated from major bean producing regions are more flexible in their choice of common bean if compared to those originated from least or none bean producing areas. Moreover, joint decision making when purchasing the beans increased the number of choice of common bean types. Based on Gillespie \& Johnson-Askew (2009), in a household attributes such as personal food knowledge, skills and other human resources contributes to the food and eating alternatives available at home.

\section{Conclusion and Implications}

Findings from this study seek to inform stakeholders and actors with respect to common bean types that are most and least chosen by consumers in the market. The information is essential for breeders, farmers and sellers of common beans to become certain about consumers' desire and what to breed, produce and sell, respectively. Relevant institutions should therefore ensure that there is a match 
between produced common bean types and consumer preference. This can create a preference oriented market which is beneficial for the respective chain actors in a sub sector.

Also, consumers' flexibility in choices of different common bean types reflects how consumers through household heads are diverse in their choices. Thus, considerable efforts to breed, produce and sell common beans with specific attributes can be the best way to fulfil consumers' desires. Meeting the varied demand of consumers, means increasing the range of choices that appeal to consumers. Moreover, the significant influence of the cultural and societal factors entails how they are important in shaping consumer preferences in choice of common beans.

Although individual domestic place of origin, consumers eating habits and household food purchase decisions were the only cultural and societal factors studied, future studies in this area may include other cultural/societal factor like belief, value, religion and norms by finding appropriate proxies to study consumer preferences on bean sub sector. Also, the common bean attributes considered in this study were colour, grain size, cooking time and gravy quality. However, it is likely that there are other attributes of common bean that are important to consumers beyond what was considered in this study. Future studies are advised to reshape the attribute levels that considered in this study or include other common bean attributes like flatulence, keeping quality and beans swelling capacity and see if they are pleasant to consumers at household level.

\section{Acknowledgements}

Authors gratefully acknowledge funding from Feed the Future Legume Innovation Lab and African Economic Research Consortium (AERC) through the Collaborative Masters of Agricultural and Applied Economics (CMAAE) programme to make the study possible.

\section{Conflicts of Interest}

The authors declare that they have no competing interests.

\section{References}

Abate, T. (Ed.) (2012). Four Seasons of Learning and Engaging Smallholder Farmers. Progress of Phase I. International Crops Research Institute for the Semi-Arid Tropics.

Abate, T., \& Orr, A. (2012). Research and Development for Tropical Legumes: Towards a Knowledge-Based Strategy. Journal of SAT Agricultural Research, 10, 1-12.

Abdullahi Farah, A., Zainalabidin, M., \& Ismail, A. L. (2011). The Influence of Socio-Demographic Factors and Product Attributes on Attitudes towards Purchasing Special Rice among Malaysian Consumers. International Food Research Journal, 18, $1135-1142$.

Akibode, S., \& Maredia, M. (2012). Global and Regional Trends in Production, Trade and Consumption of Food Legume Crops. Staff Paper 2021-10, Michigan State University. 
Alessandro, S., \& Luisa, S. (2014). The Relationship between Product and Consumer Preference for Agri-Food Product: "Red Orange of Sicily" Case. IERI Procedia, 8, 52-59. https://doi.org/10.1016/j.ieri.2014.09.010

Blake, C. M. E., Wethington, E., Farrell, T. J., Bisogni, C. A., \& Devine, C. M. (2011). Behavioral Contexts, Food-Choice Coping Strategies, and Dietary Quality of a Multiethnic Sample of Employed Parents. Journal of the American Dietetic Association, 111, 401-407. https://doi.org/10.1016/j.jada.2010.11.012

Cameron, C., \& Trivedi, P. (1986). Econometric Models Based on Count Data: Comparisons and Applications of Some Estimations and Tests. Journal of Applied Econometrics, 1, 29-53. https://doi.org/10.1002/jae.3950010104

Chadwick, P. M., Crawford, C., \& Ly, L. (2013). Human Food Choice and Nutritional Intervention. Nutrition Bulletin, 38, 36-42. https://doi.org/10.1111/nbu.12005

Cohen, D. A., \& Babey, S. H. (2012). Contextual Influences on Eating Behaviors: Heuristic Processing and Dietary Choices. Obesity Reviews, 13, 766-779. https://doi.org/10.1111/j.1467-789X.2012.01001.x

Devine, C. M., Farrell, T. J., \& Blake, C. E. (2009). Work Conditions and the Food Choice Coping Strategies of Employed Parents. Journal of Nutrition and Education Behaviour, 41,365-370. https://doi.org/10.1016/j.jneb.2009.01.007

FAOSTAT (Food and Agriculture Organization Corporate Statistical Database) (June 2020). Food and Agriculture Organization: Country Agricultural Statistical Report. http://faostat3.fao.org/browse/Q/QC/E

Gillespie, A. M. H., \& Johnson-Askew, W. L. (2009). Changing Family Food and Eating Practices: The Family Food Decision-Making System. Annals of behavioral Medicine, 38, 123-300. https://doi.org/10.1007/s12160-009-9122-7

Gitonga, H. (2015). Analysis of Consumer Preference in Product Attributes: A Case of Common Beans in Kiambu County Kenya (pp. 53-90). Unpublished Dissertation for Award of MSc Degree at Kenyatta University.

Glanz, K., Basil, M., \& Maibach, E. (1998). Why American Eat What They Do: Taste, Nutrition, Cost, Convenience, and Weight Control Concern as Influences on Food Consumption. Journal of American Dietetic Association, 10, 1118-1126. https://doi.org/10.1016/S0002-8223(98)00260-0

Hella, J. P., Chilongo, T., Mbwag, A. M., Bokosi, J., Kabambe, V., Riches, C., \& Massawe, C. L. (2013). Participatory Market-Led Cowpea Breeding in Sub-Saharan Africa: Evidence Pathway from Malawi and Tanzania. Merit Research Journal of Agricultural Science and Soil Science, 1, 11-18.

Katungi, E., Louise, S., David, K., Farrow, A., \& Beebe, S. (2011). Relative Importance of Common Bean Attributes and Variety Demand in the Drought Areas of Kenya. Journal of Development and Agricultural Economics, 3, 411-422. https://doi.org/10.5897/JDAE.9000108

Lancaster, K. (1966). Change and Innovation in the Technology of Consumption. The American Economic Review, 56, 14-23.

Leterme, P. (2002). Recommendations by Health Organizations for Pulse Consumption. British Journal of Nutrition, 88, 239-242. https://doi.org/10.1079/BJN2002712

Lima, J. P. M., Costa, S. A., Brandão, T. R. S., \& Rocha, A. (2021). Food Consumption Determinants and Barriers for Healthy Eating at the Workplace-A University Setting. Foods, 10, Article No. 695. https://doi.org/10.3390/foods10040695

Louviere, J. J., Hensher, D. A., \& Swait, J. D. (2000). A Stated Choice Method: Analysis and Applications. Cambridge University. (In Press) 
Mishili, J. F., Temu, A. A., Fulton, J., \& Lowenberg-DeBoer, J. (2011). Consumer Preference as Drivers of the Common Beans Trade in Tanzania: A Marketing Perspective. Journal of International Food and Agribusiness Marketing, 23, 110-127. https://doi.org/10.1080/08974438.2011.558761

Mundua, J. (2010). Estimation of Consumer Preference for Cowpea Varieties in Kumi and Soroti District, Uganda. Unpublished Dissertation for Award of MSc Degree at Makerere University.

Nassary, E. K., Baijukya, F., \& Ndakidemi, A. (2020). Assessing the Productivity of Common Bean in Intercrop with Maize across Agro-Ecological Zones of Smallholder Farms in the Northern Highlands of Tanzania. Agriculture, 10, Article No. 117. https://doi.org/10.3390/agriculture10040117

Nedumaran, S., Abinaya, P., Jyosthnaa, P., Shraavya, B., Parthasarathy, R., \& Bantilan, C. (2015). Grain Legumes Production, Consumption and Trade Trends in Developing Countries (64 p). Working Paper Series No 60. ICRISAT Research Program, Markets, Institution and Policies. International Crop Research Institute for the Semi-Arid Tropics.

Nedumaran, S., Abinaya, P., Shraavya, B., Parthasarathy, R., \& Bantilan, C. (2013). Grain Legumes Production, Consumption and Trade Trends in Developing Countries-An Assessment and Synthesis. Series paper Number 3. ICRISAT Research Program, Markets, Institution and Policies.

Ogundele, O. (2014). Factors Influencing Consumers' Preference for Local Rice in Nigeria. African Journal of Marketing Management, 6, 49-55. https://doi.org/10.5897/AJMM2011.048

Parraga, I. (1990). Determinants of Food Consumption. Journal of the American Dietetic Association, 90, 661-663. https://doi.org/10.1016/S0002-8223(21)01599-6

Riet, J., Sijtsema, S. J., Dagevos, H., \& De, G.-H. (2011). The Importance of Habits in Eating Behavior. An Overview and Recommendation for Future Research. Appetite, 57, 585-596. https://doi.org/10.1016/j.appet.2011.07.010

Ronner, E., \& Giller, K. E. (2013). Background Information on Agronomy, Farming System and Ongoing Projects on Grain Legumes in Tanzania (33 p). https://www.N2Africa.org

Saba, I., Sofi, P. A., Kandoliya, U. K., \& Baba, Z. A. (2015). Natural Variation for Seed Physical, Biochemical, and Culinary Traits in Common Bean (Phaseolus vulgaris L.). Current Botany, 6, 1-8. https://doi.org/10.19071/cb.2015.v6.2820

Vartanian, L. R., Herman, C. P., \& Wansink, B. (2008). Are We Aware of the External Factors that Influence Our Food Intake? Health Psychology, 27, 533-538.

https://doi.org/10.1037/0278-6133.27.5.533

Wahl, D. R., Villinger, K., König, L. M., Ziesemer, K., Schupp, H. T., \& Renner, B. (2017). Healthy Food Choices Are Happy Food Choices: Evidence from a Real Life Sample Using Smartphone Based Assessments. Scientific Reports, 7, Article No. 17069. https://doi.org/10.1038/s41598-017-17262-9 